\title{
Menstrual Cycle
}

National Cancer Institute

\section{Source}

National Cancer Institute. Menstrual Cycle. NCI Thesaurus. Code C16838.

The Menstrual Cycle involves regularly recurring hormonal changes and physiologic

endometrial changes during the reproductive period in human females, and some

primates, and culminates in partial sloug hing of the endometrium (menstruation) in the absence of fertilization. For most women, one cycle takes 28 days. $(\mathrm{NCl})$ 